\title{
Diagnosis and surgical treatment of coronary artery fistula
}

\author{
J.P. ROOS, H. HARTMAN, H. VAN DER SCHAAR, \\ a nd A. G. B R O M
}

Departments of Cardiology and Thoracic Surgery, Academisch Ziekenhuis, Leiden, The Netherlands

\begin{abstract}
Phonocardiography is of great importance in distinguishing coronary artery fistula from other anomalies with a continuous murmur. The presence of this murmur at the apex must be regarded as an important characteristic of a coronary artery fistu!a, especially when the maximum diastolic murmur is found at the apex.

Although coronary artery fistula may be symptomless for a long time, surgical treatment is desirable in most cases. Extracorporeal circulation should be used in all operations for coronary artery fistula to avoid ligation of the wrong artery or failure to c'ose all fistula orifices.
\end{abstract}

A coronary artery fistula is an abnormal communication between one or both coronary arteries and one of the heart cavities or large vessels (McNamara and Gross, 1969). The fistula may or may not be associated with other abnormalities of the heart.

In oldar children and adults, an abnormal origin of a coronary artery from the pulmonary artery can be regarded as a coronary fistula. This abnormality, which usually involves the left coronary artery, is compatible with life only if there is a direct communication-and therefore a fistula-with the right coronary artery. In these patients, oxygen-rich blood flows from the right coronary artery into the left. In cases in which this communication is absent, the patient is bound to die at an early age because the myocardium is supplied with oxygen-poor blood from the pulmonary artery.

The diagnosis of a coronary artery fistula can offer difficulties. The murmur and all other clinical features can be very suggestive of a patent ductus arteriosus, for instance, and even right heart catheterization cannot always prevent an erroneous diagnosis.

Biörck and Crafoord (1947) were the first to describe an aberrant coronary vessel to the pulmonary artery, which they treated successfully by operation. A fair number of reports have since been published on this anomaly, and most of these reports discuss the differential diagnosis from other abnormalities accompanied by a continuous murmur (Nadas, Gamboa, and Hugenholtz, 1964 ; Björk and Björk, 1965; Noonan and Spencer, 1965 ; Sterz, Pailer, and Müller, 1965 ; Talner, Halloran, Mahdavy, Gardner, and
Hipona, 1965 ; Corone, Binet, Langlois, Leiva, Lainee, Geschwind, and Rochemaure, 1966; Wesselhozft, Fawcett, and Johnson, 1968 ; Barnes, Cheung, Anthony, and Wu, 1969).

This paper discusses nine cases of coronary artery fistula with special reference to the phonocardiographic diagnosis of this congenital anomaly.

\section{CASE REPORTS \\ (in chronological order)}

CASE 1 Patient W. was a 5-year-old girl without symptoms. Phonocardiographic examination disclosed a continuous murmur along the left sternal border : both the systolic and the diastolic murmurs had a late maximum. At the apex, these murmurs were distinct also. In the left as well as the right subclavicular region there was a holosystolic murmur and a slight late diastolic murmur. The electrocardiogram showed no abnormality. Heart catheterization disclosed an oxygen jump in the right ventricle. The pressure in the right ventricle was normal. The aortogram showed, at the heart apex, a vascular convolution which communicated with the left coronary artery (Fig. 1). The condition was diagnosed as coronary artery fistula between the left coronary artery and the right ventricle. An operation was performed, using extracorporeal circulation. The vascular convolution was incised and it was found that the left as well as the right coronary artery opened up into the right ventricle through this convolution. The exits of both coronary arteries in the vascular convolution were ligated.

The post-operative course was uneventful, and a follow-up phonocardiogram recorded a few months later disclosed nothing abnormal.

CASE 2 Patient D. was a 21-year-old woman with vague complaints of exertional dyspnoea. At age 17 


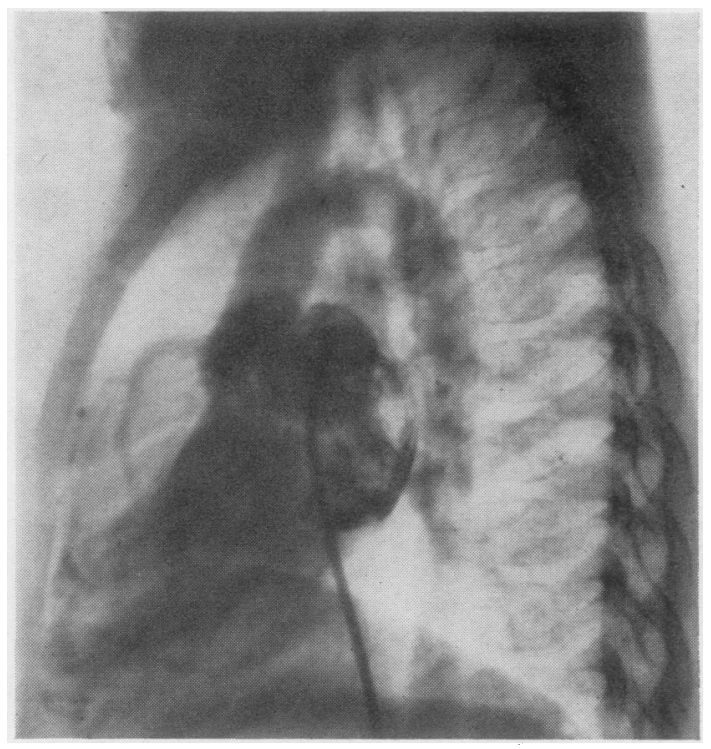

FIG. 1. Case 1. Aortogram shows a vascular convolution at the apex which communicates with the left coronary artery.

she had elsewhere undergone a left-sided thoracotomy for what was believed to be a patent ductus arteriosus, which was not found at this operation. The present phonocardiographic examination revealed a holosystolic and holodiastolic murmur along the left sternal border. There was no interval between the heart sounds and murmurs. At the apex, too, there was a systolic and a fairly loud diastolic murmur (Fig. 2). The electrocardiogram was normal. Heart catheterization disclosed an oxygen jump in the pulmonary artery. No angiocardiography was carried out. The condition was diagnosed as a coronary artery fistula to the pulmonary artery and an operation was performed using extracorporeal circulation. External examination of the heart showed that virtually all branches of both coronary arteries were dilated. The pulmonary artery was opened and it was found that the right coronary artery opened up into the pulmonary artery. The orifice was closed from the inside.

The post-operative course was uneventful. Followup after two years revealed no symptoms. The electrocardiogram was normal, as was the phonocardiogram.

Case 3 Patient $H$. was a boy aged 10 without complaints. Phonocardiographic examination revealed a continuous murmur along the left sternal border. The systolic as well as the diastolic murmur had a late maximum. Both murmurs were present also at the apex. In the left and right subclavicular regions there was a holosystolic murmur combined with a slight, short diastolic murmur. The electrocardiogram was normal. The condition was diagnosed as patent ductus arteriosus, but at operation the ductus was found to be closed. Further exploration disclosed a coronary: artery fistula arising from a branch of the right coronary artery and extending to the right ventricle? At its entry into the right ventricle the afferent artery was ligated and cut.

The post-operative course was uneventful. A follow- $-\frac{\bar{T}}{\bar{D}}$ up phonocardiogram recorded two years later dis closed no abnormality.

case 4 Patient vW. was a 3 -year-old boy without $\overrightarrow{0}$ symptoms. Phonocardiographic examination revealeda holosystolic crescendo/decrescendo murmur along the left sternal border, in combination with a slight diastolic murmur. A systolic murmur and a short protodiastolic murmur were present at the apex. The left and right subclavicular regions contained a sys- $-\omega$ tolic murmur, but no diastolic murmur was recorded Heart catheterization disclosed normal pressures ando failed to show an oxygen jump. It was possible to pass a catheter through a coronary artery into the left atrium. The angiocardiogram also showed this communication (Fig. 3). The condition was diagnosed as a coronary artery fistula to the left atrium; at operation it was found to arise from the left coro- $\theta$ nary artery. Partial clamping of the left atrium made it possible to close the fistula orifice from the inside.

The post-operative course was uneventful. AS

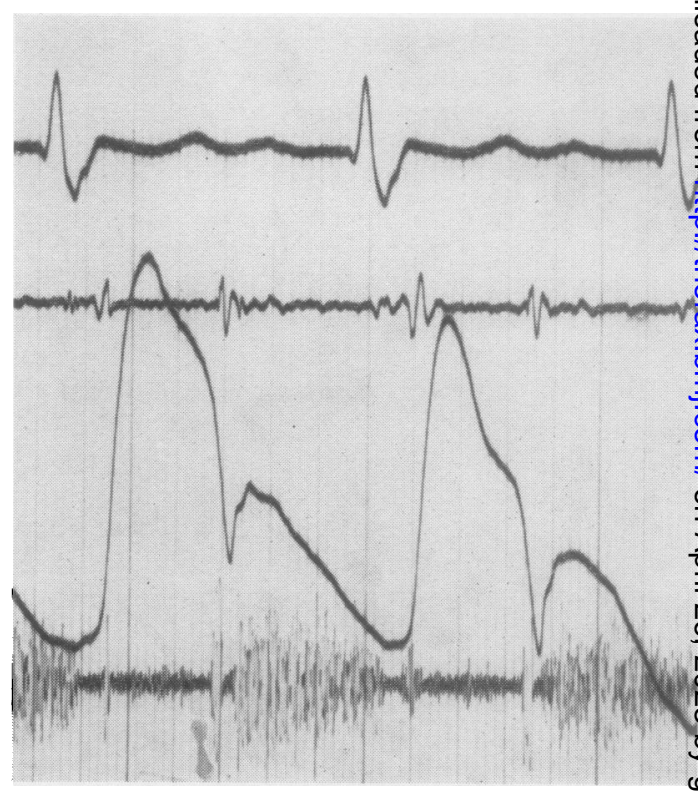

FIG. 2. Case 2. Phonocardiogram.

Top tracing: ' electrocardiogram lead 2.

Second tracing: low frequency phonocardiogram. Third tracing: carotid tracing.

Bottom tracing: high frequency phonocardiogram at⿱ the apex shows a slight holosystoli murmur and a fairly loud diastolie murmur.

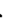




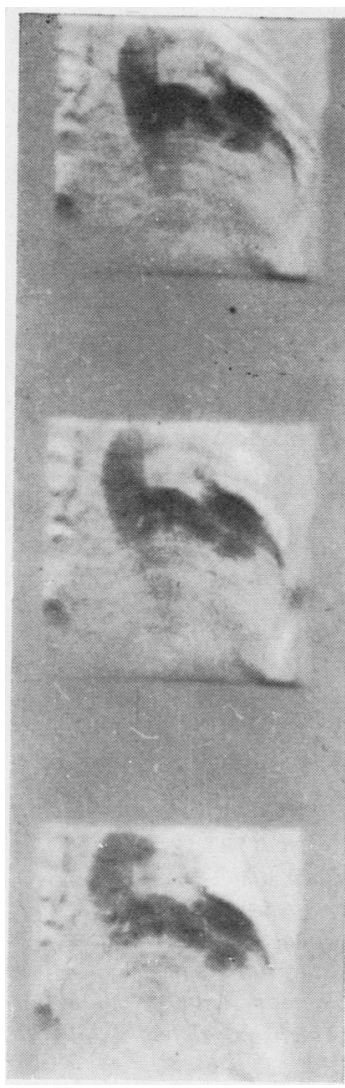

follow-up a few years later the phonocardiogram was normal.

CASE 5 Patient L. was a boy aged 5 weeks, who showed marked progressive cyanosis. Phonocardiographic examination showed a systolic murmur with a late start along the left sternal border ; this murmur continued until the second sound. A slight diastolic murmur was present also. At the apex there was a systolic murmur with a late start, combined with a slight diastolic murmur. Heart catheterization yielded the following values:

$\begin{array}{lcc} & \text { Saturation } & \text { Pressure } \\ \text { Superior vena cava } & 28 \% & \\ \text { Inferior vena cava } & 40 \% & \\ \text { Right atrium } & 45 \% & 3 \mathrm{~mm} . \mathbf{H g} \\ \text { Right ventricle } & 41 \% & 100 / 10 \\ \text { Pulmonary veins } & 95 \% & \\ \text { Left atrium } & 60 \% & \\ \text { Left ventricle } & 63 \% & \\ \text { Femoral artery } & & 70 / 0\end{array}$

The angiocardiogram could not readily be interpreted. The contrast medium injected into the right ventricle seemed to disappear from it through an insufficient tricuspid valve and thrcugh a convoluted vessel. The pulmonary artery did not fill. In the course of an exploratory thoracotomy, irreversible cardiac standstill occurred. Necropsy disclosed the following pathological anatomical abnormalities: Fistula from left coronary artery to right ventricle; absence of right coronary artery; atresia of pulmonary artery; stenosis of tricuspid valve; atrial septal defect ; ruptured membranous septum; patent ductus arteriosus.

CASE 6 Patient M. was a 16-year-old girl without symptoms. Phonocardiographic examination revealed a loud continuous murmur along the left sternal border. In the left lateral recumbent position there was a protosystolic decrescendo murmur at the apex, with a fairly loud holodiastolic murmur (Fig. 4). A continuous murmur was present in the left and right subclavicular regions. In the venous curve the $\mathrm{V}$-wave was as high as the a-wave. Heart catheterization disclosed an oxygen jump in the right atrium. The aortogram revealed a communication between the left coronary artery and the right atrium (Fig. 5). An

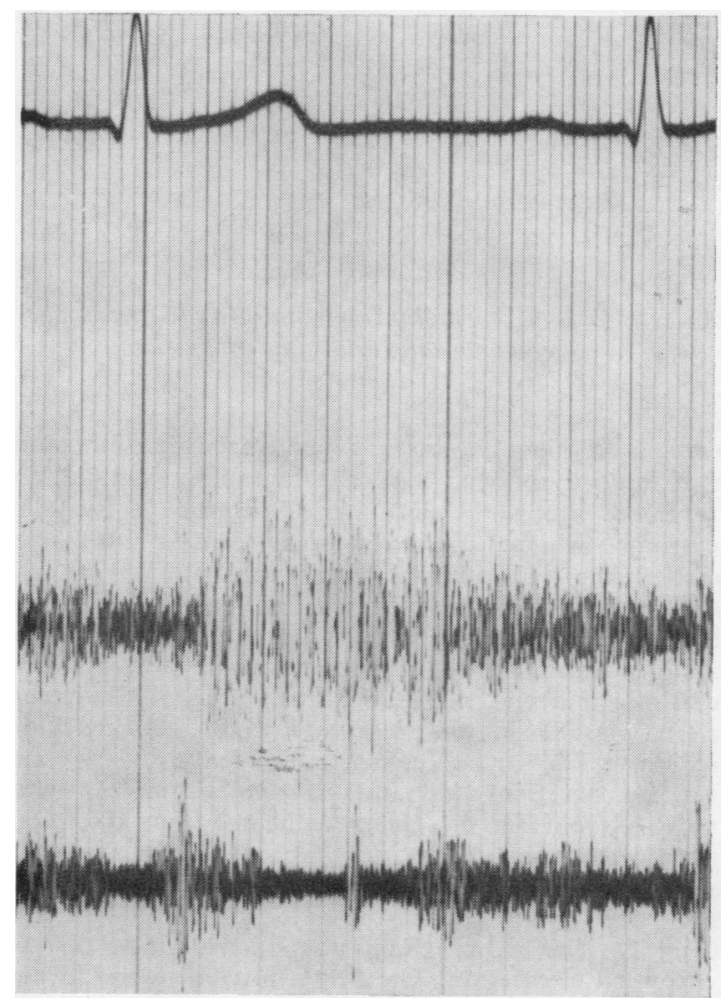

FIG. 4. Case 6. Phonocardiogram.

Top tracing: $\quad$ electrocardiogram lead 2.

Second tracing: recorded along left sternal border, shows a continuous murmur.

Bottom tracing: recorded at the apex, shows a protosystolic murmur and a pandiastolic murmur. 
operation was performed using extracorporeal circulation. The right atrium was opened and two fistula orifices were closed from the inside.

The post-operative course was uneventful. A followup phonocardiogram recorded a few months later revealed no abnormality.

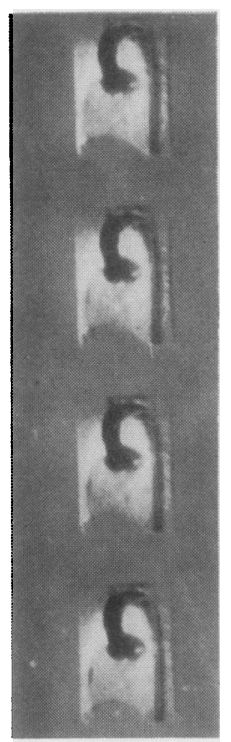

FIG. 5. Case 6. Aortogram shows a dilated left coronary artery, which communicates with the right atrium.

CASE 7 Patient P. was a woman aged 52 with mild exertional dyspnoea. Phonocardiographic examination revealed, along the left sternal border, a systolic murmur which continued decrescendo until the second heart sound. The latter was followed immediately by a diastolic murmur. In the left lateral recumbent position there was, at the apex, a holosystolic murmur with a late maximum and a holodiastolic murmur. A systolic and a diastolic murmur were present in the left and right subclavicular regions. The most conspicuous feature was the venous curve, in which the $\mathrm{V}$-wave was higher than the a-wave (Fig. 6). Heart catheterization disclosed an oxygen jump in the right atrium. The aortogram seemed to indicate that the left as well as the right coronary artery opened up into the right ventricle (Fig. 7). The right atrium was opened under extracorporeal circulation. The fistula proved to end in the coronary sinus. The coronary sinus was opened from the outside, and the afferent arteries were ligated.

The post-operative course was uneventful. At follow-up a few months later the phonocardiogram was normal. The exertional dyspnoea had improved.

CASE 8 Patient B. was an 11-year-old boy with exertional dyspnoea and cyanosis. Phonocardiographic

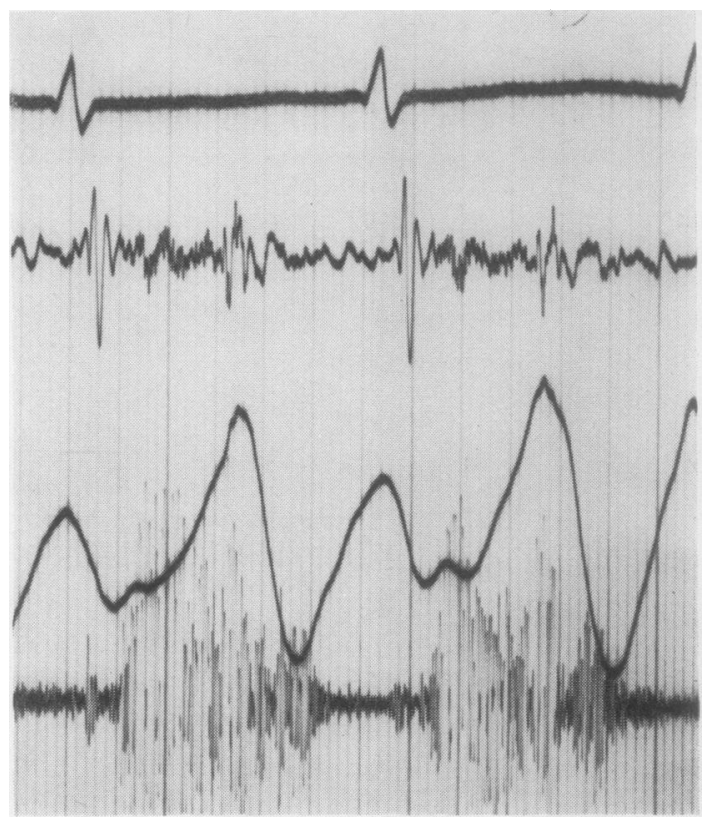

fIG. 6. Case 7. Phonocardiogram.

Top tracing: $\quad$ electrocardiogram lead 2.

Second tracing: low frequency phonocardiogram along left sternal border.

Third tracing: jugular venous tracing shows a $v$-wave which is higher than the a-wave.

Bottom tracing: high frequency phonocardiogram shows a systolic murmur starting $0.06 \mathrm{sec}$. after the onset of the first heart sound and a short protodiastolic murmur.

examination disclosed a continuous murmur with its maximum in the left second intercostal space. At the apex there was a systolic murmur with a late maximum and a diastolic murmur. Heart catheterization and angiocardiography revealed atresia of the pulmonary artery, ventricular septal defect. and marked desaturation in the aorta. The coronary arteriography also showed a coronary fistula communicating with the pulmonary artery (Fig. 8). A total surgical correction was performed analogous to that of Rastelli. Ongley, Davis, and Kirklin (1965). The peripheral pulmonary artery trunk, supplied by the left coronary artery, was re-connected to the right ventricle by means of an aortic homograft (including sufficient valves) and a Dacron graft. The ventricular septal defect was closed and the communication between the left coronary artery and the pulmonary artery was ligated. Duplication of the aortic arch was incidentally found.

The post-operative course was uneventful and the follow-up phonocardiogram was normal. 


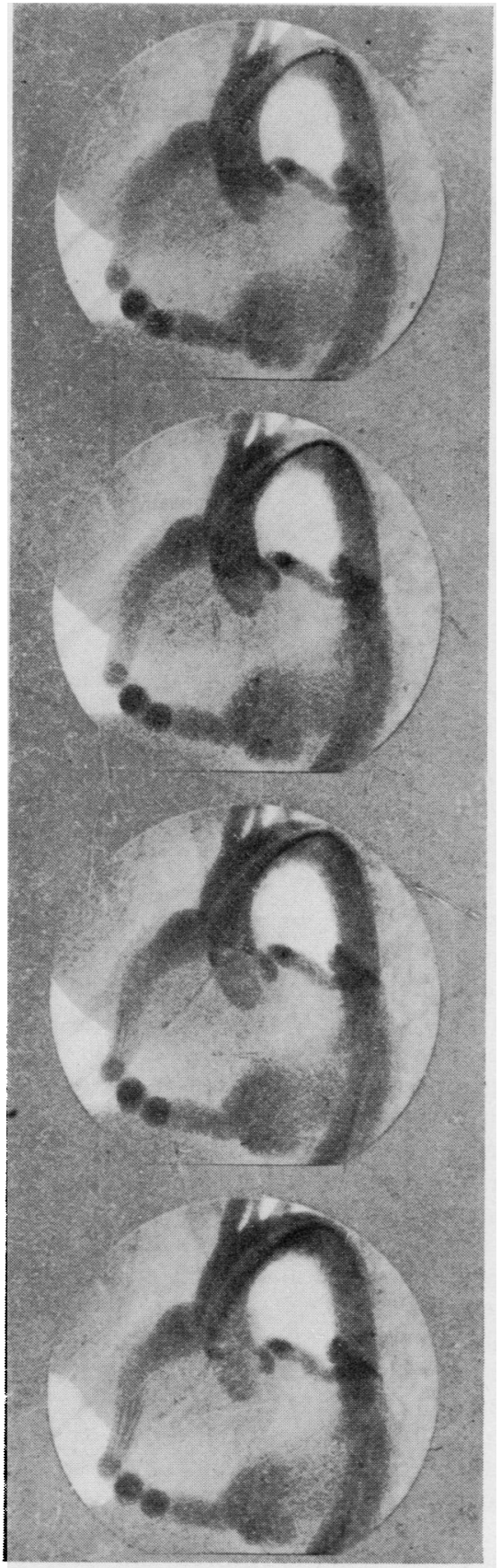

rIG. 7. Case 7. Aortogram shows a dilated right and left coronary artery which communicates with the right ventricle.

CASE 9 Patient vO. was a woman aged 53 without symptoms. Phonocardiographic examination disclosed a crescendo/decrescendo systolic murmur along the

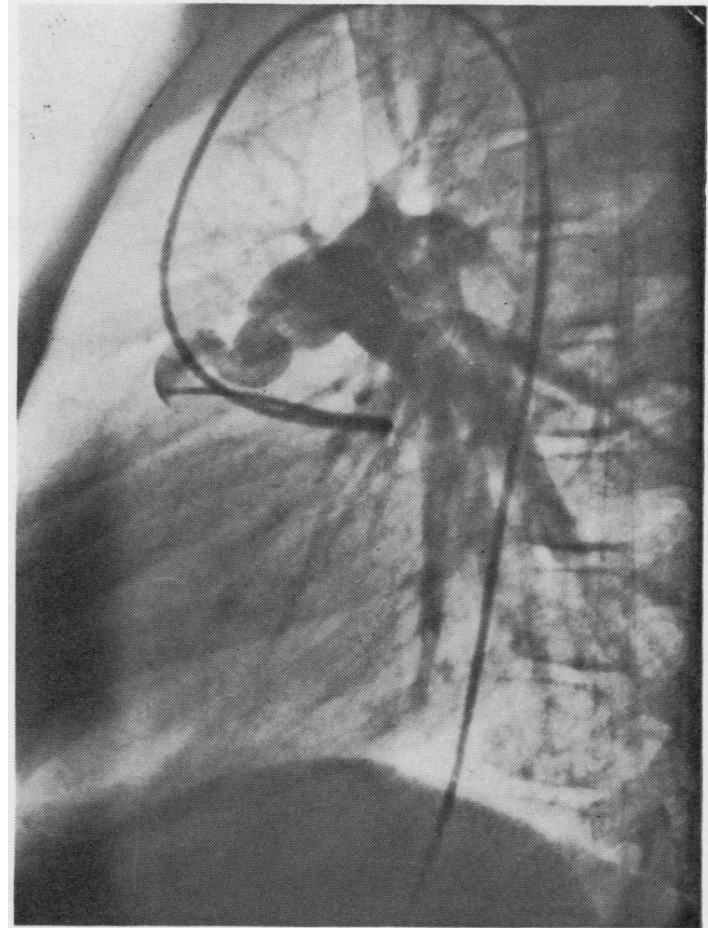

FIG. 8. Case 8. Coronary arteriography shows a dilated left coronary artery in communication with the pulmonary artery.

left sternal border, in combination with a protodiastolic murmur. At the apex, too, a systolic-diastolic murmur was present (Fig. 9). The electrocardiogram showed a sinus rhythm with a slight ST depression and flat $T$-waves over the left precordium. Heart catheterization disclosed no oxygen jump in the right heart. Coronary arteriography showed a tortuous, highly distended descending branch of the left coronary artery, which probably emptied into the left ventricle (Fig. 10). The circumflex artery and the right coronary artery were normal. Radiologically, the left ventricle was slightly enlarged. In view of the patient's age and the absence of complaints, surgical treatment was not resorted to at this time.

\section{DISCUSSION}

A coronary artery fistula is a fairly rare congenital anomaly. Nearly always, the blood supply to the heart is sufficient and anginal symptoms are therefore absent in most cases; nor are there electrocardiographic changes of significance.

The most common type of coronary artery fistula is that between the right coronary artery and the right heart, usually the right ventricle. Blood flows from the high-pressure artery to the low-pressure part of the heart, both in systole 


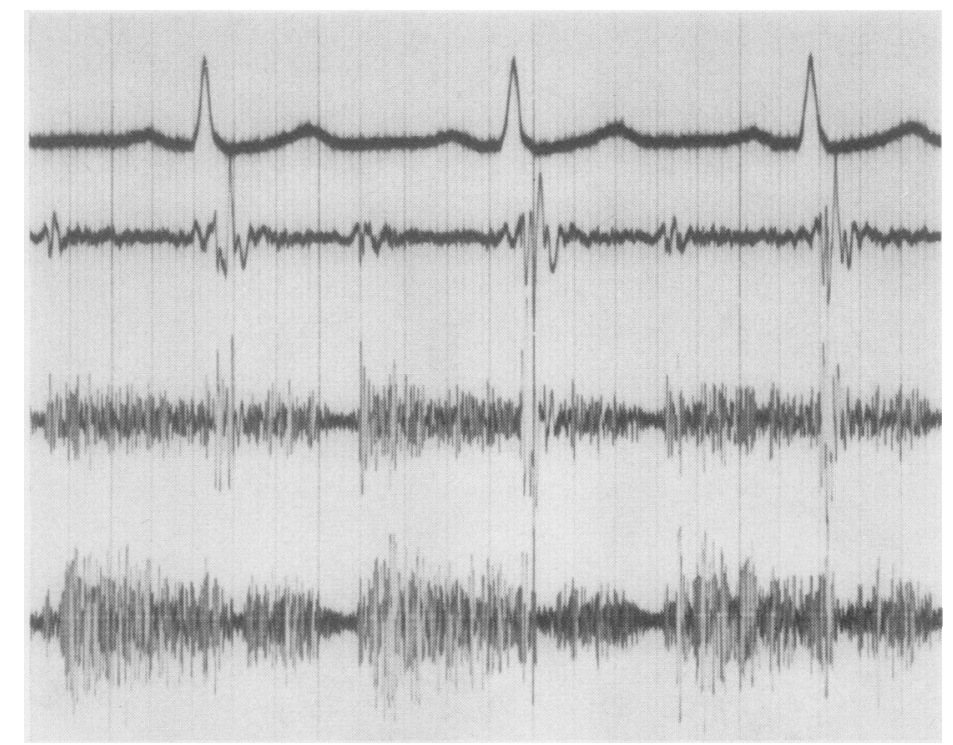

FIG. 9. Case 9. Phonocardiogram recorded at the apex. Top tracing: $\quad$ electrocardiogram lead 2.

Second tracing: low frequency phonocardiogram $(35 \mathrm{~Hz})$ at the apex.

Third tracing: $\quad 70 \mathrm{~Hz}$ phonocardiogram at the apex.

Bottom tracing: high frequency phonocardiogram

$(140 \mathrm{~Hz})$ at the apex.

and in diastole. Signs and symptoms are dependent on the size of the shunt, as they are in the case of shunt between the right and the left heart. Severe pulmonary hypertension has not been described in association with a coronary artery fistula. Other anomalies which clinically resemble a coronary artery fistula and also produce a systolic-diastolic murmur are patent ductus arteriosus, aorto-pulmonary fenestration, fistula between the aorta and the right ventricle, and ventricular septal defect with aortic insufficiency. Auscultation and phonocardiography are of great importance in the differential diagnosis from these conditions. In the case of a coronary artery fistula the systolic-diastolic murmur is always present at the apex as well as to the left of the sternum. The maximum of this murmur is localized either low along the left sternal margin or at the apex, but never in the subclavicular regions. In other anomalies accompanied by a systolic-diastolic murmur, this murmur is not present at the apex, and its maximum lies either along the left sternal border or in the subclavicular regions. The presence of this murmur at the apex must be regarded as an important characteristic of coronary artery fistula, particularly when the maximum diastolic murmur is found at the apex.
Selective coronary arteriography can confirm the diagnosis, although even then it remains difficult to establish in which part of the heart the fistula is situated. The localization of the fistula orifice in the right heart may be shown by coronary arteriography combined with heart catheterization (which discloses an oxygen jump). Of course the latter method cannot be used when the fistula opens up into the left heart, in which case coronary arteriography is the sole guide.

In view of the risk of bacterial endocarditis, 윽 coronary artery fistula gensrally requires opera- $\rightarrow$ tion, even when it is asymptomatic. In our lastmentioned patient (case 9), we refrained from $N$ surgery for the time being in view of her fairly advanced age (53 years); in this case, however, $\mathcal{O}$ electrocardiographic changes did exist, and an $\mathbb{W}$ operation may after all be necessary if these should prove to be progressive.

SURGICAL TREATMENT Biörck and Crafoord were $\stackrel{?}{-}$ the first to treat a coronary artery fistula by ${ }^{\circ}$ surgery in 1947. Their patient had a fistula be- $\frac{O}{\mathbb{D}}$ tween the pulmonary artery and a branch of a $\stackrel{\oplus}{\oplus}$ coronary artery. This fistula was removed by $\mathbb{Q}$ ligating the aberrant vessel near the pulmonary artery. This procedure has since been used by 


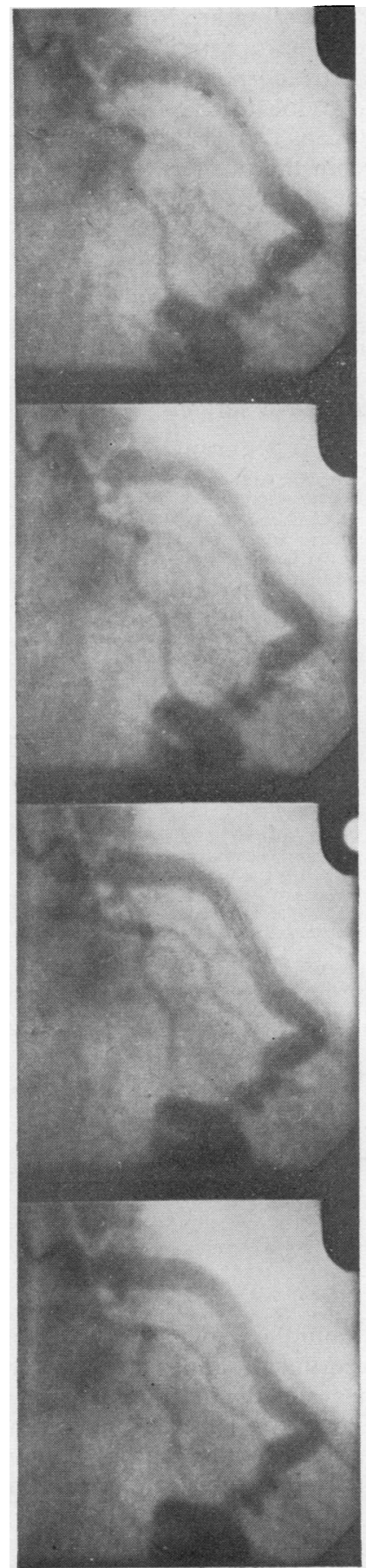

FIG. 10. Case 9. Coronary arteriography shows a dilated descending branch of the left coronary artery which probably communicates with the left ventricle. several other surgeons. They all used in principle the same technique, that is to say, ligation or severance of the aberrant afferent artery. That this therapy is not devoid of risks is shown in a publication by Lam, Taber, Ziegler, and Green (1968), which describes ventricular fibrillation in a patient in whom one normal artery was inadvertently ligated: the continuity was unsuccessfully restored with the aid of extracorporeal circulation. We, too, have found that it is not always possible to establish with certainty which coronary branches communicate with the fistula orifice. A different surgical technique was described by Swan, Wilson, Woodwark, and Blount, Jr. (1959) - closure of the fistula orifice under direct vision with the aid of circulatory arrest and hypothermia. This procedure also has the advantage of leaving the continuity of the artery intact.

McNamara and Gross (1969) concluded from personal experience and from the literature that the surgical technique used depends on the localization of the fistula, which can be established by means of selective coronary arteriography. A fistula not readily accessible because of its position, say, on the posterior side of the heart, requires an operation under extracorporeal circulation. The fistula orifice can then be closed either from the inside or from the outside. Extracorporeal circulation is required also in operations for coronary artery fistula with multiple orifices. The above-mentioned authors maintain that ligation of the fistula orifice without the aid of extracorporeal circulation is feasible only when it is evident that only a single, readily accessible orifice exists.

Our experience and the above-mentioned literature indicates that external ligation alone cannot rule out errors such as ligation of the wrong artery or failure to close all fistula orifices. Pre-operative coronary arteriography is likewise unable to eliminate the possibility of these errors.

We believe that it is advisable to resort to extracorporeal circulation in all operations for coronary artery fistula. This makes it possible to ascertain the position of the fistula orifice from the outside, by incision of the dilated coronary artery. After all, the localization of the fistula in this artery is suggested by the fact that the dilated coronary artery resumes a normal calibre at this site. Direct closure of the orifice can then be effected from the inside or from the outside. Intracardiac inspection should follow, if necessary, to ensure that all fistula orifices have been closed.

If the coronary artery fistula results from an 
abnormal origin of the coronary artery from the pulmonary artery, then reimplantation into the aorta with the aid of a venous graft must be considered. One of the above described patients had such an anomaly. As we described, this fistula was abolished by closure of the orifice in the pulmonary artery. However, re-implantation into the aorta is probably to be preferred for subsequent cases.

In some patients it is impossible to operate on a coronary artery fistula immediately. These are patients who owe their lives to the presence of this fistula, e.g., our patient no. 8. In this patient the entire pulmonary circulation was supplied with blood by the coronary artery fistula, and consequently this fistula could not be closed immediately. Instead we had to combine the fistula operation with reconstruction of the pulmonary artery trunk to the right ventricle ; and in addition a ventricular septal defect was closed. Only then was it possible to close the fistula.

\section{SUMMARY}

Nine cases of coronary artery fistula are presented, with special emphasis on the importance of phonocardiographic findings as an aid in differentiation from other anomalies accompanied by a systolicdiastolic murmur. At least in our series it was evident that, independent of concomitant cardiac anomalies, coronary artery fistula is always associated with a systolic-diastolic murmur localized along the left sternal border and at the apex. The presence of this murmur at the apex must be regarded as an important characteristic of a coronary artery fistula, especially when the maximum diastolic murmur is found at the apex.

Haemodynamically, a coronary artery fistula is to be regarded as a left-to-right shunt or, if the coronary artery communicates with the left atrium or left ventricle, as a left-to-left shunt, the size of which determines the symptoms produced.
The electrocardiogram is normal in the majority $\overrightarrow{\vec{s}}$ of cases. Coronary artery fistula requires opera $=$ tion under extracorporeal circulation; this makes $\frac{C}{0}$ it possible to locate the fistula orifice from the $\overline{\bar{n}}$ outside. It can then be closed either from the $\vec{\varnothing}$ inside or from the outside.

When the fistula results from an abnormalos origin of the coronary artery in the pulmonary $\overrightarrow{0}$ artery, re-implantation must be considered.

In some patients immediate closure of the $\vec{\omega}$ coronary artery fistula is impossible because it is the fistula that keeps them alive. In such cases, closure of the fistula must be preceded by exten-or sive reconstructive surgery.

\section{REFERENCES}

Barnes, R. J., Cheung, Anthony C. S., and Wu, Raymond W. Y음 (1969). Coronary artery fistula. Brit. Heart J., 31, 299.

Biörck, G., and Crafoord, C. (1947). Arteriovenous aneurysm on the pulmonary artery simulating patent ductus arteriosus Botalli. Thorax, 2, 65.

Björk, V. O., and Björk, L. (1965). Coronary artery fistula. J. thorac. cardiovasc. Surg., 49, 921.

Corone, P., Binet, J. P., Langlois, J., Leiva, A., Lainee, R., Geschwind $\vec{\omega}$ H., and Rochemaure, J. (1966). Coronaire gauche anormale chez l'adulte. Arch. Mal. Coeur, 59, 273.

Lam, C. R., Taber, R. E., Ziegler, R. F., and Green, E. W. (1968). Surgical treatment of anomalies of the coronary arteries. Progr. cardiovasc. Dis., 11, 156. McNamara, J. J., and Gross, R. E. (1969). Congenital coronary
artery fistula. Surgery, 65, 59.

Nadas, A. S., Gamboa, R., and Hugenholtz, P. G. (1964). Anomalous left coronary artery originating from the pulmonary artery $\mathbb{D}$
Circulation, 29, 167 .

Noonan, J. A., and Spencer, F. C. (1965). Single coronary artery with coronary arteriovenous fistula communicating with the right ventricle. Amer. J. Cardiol., $15,848$.

Rastelli, G. C., Ongley, P. A., Davis, G. D., and Kirklin, J. W. (1965) Surgical repair for pulmonary valve atresia with coronary pulmonary artery fistula. Report of case. Mayo Clin. Proc. 40, 521 .

Sterz, H., Pailer, R., and Müller, F. (1965). Zum Leitsymptom des kontinuierlichen systolo-diastolischen Geräusches. Arch. Kreisl. Forsch., 47, 277.

Swan, H., Wilson, J. N., Woodwark, G., and Blount, S. G. (1959) Surgical obliteration of a coronary artery fistula to right ventricle Arch. Surg., 79, 820 .

Talner, N. S., Halloran, K. H., Mahdavy, M., Gardner, T. H., andh Hipona, F. (1965). Anomalous origin of the left coronary artery from the pulmonary artery. A clinical spectrum. Amer. $J$ Cardiol., 15, 689.

Wesselhoeft, H., Fawcett, J. S., and Johnson, A. L. (1968). Anomalous origin of the left coronary artery from the pulmonary trunk? its clinical spectrum, pathology and pathophysiology, based on a review of 140 cases with seven further cases. Circulation?

\section{Norman R. Barrett}

Regular readers will notice that the name of Norman Barrett no longer appears on the outside cover of Thorax, though we are fortunate that it is still to be found among the Editorial Committee. This will be the first such occasion since the birth of the Journal nearly 25 years ago, during which time 'Pastey' has read and edited every surgical paper Thorax has published as well as nearly twice as many that were not accepted. He has always refused to compromise with unsatisfactory standards, though when the Journal started it was not always easy to find good material. $\mathrm{He}$ has stimulated countless colleagues to think, to writes and to experiment, and by his personality and example has added greatly to the stature of the Journal both in the United Kingdom and abroad. At a lunch given by the Journal Committee of the British Medical Association, at a dinner of the Council of the Thoracic Society, and at anothero of the whole Thoracic Society, all combined to wish him every happiness in his retirement and? to thank him for his tremendous contribution to thoracic surgery and its literature.

A. JOHN ROBERTSON. 